\title{
Attributable causes of colorectal cancer in China
}

\author{
Meng-Jia Gu',2, Qiu-Chi Huang ${ }^{1}$, Cheng-Zhen Bao ${ }^{1}$, Ying-Jun Li ${ }^{1}$, Xiao-Qin $\mathrm{Li}^{3}$, Ding Ye ${ }^{1}$, Zhen-Hua Ye ${ }^{1}$, \\ Kun Chen ${ }^{1^{*}}$ and Jian-Bing Wang ${ }^{1 *}$ (1)
}

\begin{abstract}
Background: Colorectal cancer is the 4th common cancer in China. Most colorectal cancers are due to modifiable lifestyle factors, but few studies have provided a systematic evidence-based assessment of the burden of colorectal cancer incidence and mortality attributable to the known risk factors in China.

Methods: We estimated the population attributable faction (PAF) for each selected risk factor in China, based on the prevalence of exposure around 2000 and relative risks from cohort studies and meta-analyses.

Results: Among 245,000 new cases and 139,000 deaths of colorectal cancer in China in 2012, we found that 115,578 incident cases and 63,102 deaths of colorectal cancer were attributable to smoking, alcohol drinking, overweight and obesity, physical inactivity and dietary factors. Low vegetable intake was the main risk factor for colorectal cancer with a PAF of $17.9 \%$. Physical inactivity was responsible for $8.9 \%$ of colorectal cancer incidence and mortality. The remaining factors, including high red and processed meat intake, low fruit intake, alcohol drinking, overweight/obesity and smoking, accounted for $8.6 \%, 6.4 \%, 5.4 \%, 5.3 \%$ and $4.9 \%$ of colorectal cancer, respectively. Overall, $45.5 \%$ of colorectal cancer incidence and mortality were attributable to the joint effects of these seven risk factors.

Conclusions: Tobacco smoking, alcohol drinking, overweight or obesity, physical inactivity, low vegetable intake, low fruit intake, and high red and processed meat intake were responsible for nearly $46 \%$ of colorectal cancer incidence and mortality in China in 2012. Our findings could provide a basis for developing guidelines of colorectal cancer prevention and control in China.
\end{abstract}

Keywords: Colorectal cancer, Risk factors, Population attributable fraction, China

\section{Background}

Colorectal cancer has ranked the third most common cancer and the fourth most common cancer cause of death worldwide, and almost 1.4 million new cases and 694,000 deaths occurred in 2012 [1]. The incidence rate is low among people aged less than 50 years, but getting strong increase with age [2]. Colorectal cancer rates are higher in some developed countries such as the Czech Republic, Japan, Australia, the majority of Western Europe and North America, which may result from the "Westernization" (such as obesity and physical inactivity) [3]. According to the WHO data, China suffered 245,000 new cases

\footnotetext{
*Correspondence: ck@zju.edu.cn; wangjianbing1980@yahoo.com ${ }^{1}$ Department of Epidemiology and Health Statistics, Zhejiang University School of Public Health, 866 Yuhangtang Road, Hangzhou 310058, China Full list of author information is available at the end of the article
}

and 139,000 deaths of colorectal cancer in 2012, which made it the fifth most common cancer in man and the fourth in women.

Recently, it is believed that no single risk factor could be responsible for risk of colorectal cancer [4]. Individuals who had higher education level or were non-Hispanic white suffered lower risk of colorectal cancer mortality [5]. Over the past few decades, a number of risk factors for colorectal cancer have been identified, including: family history of colorectal cancer [6], inflammatory bowel disease [7], diabetes [8], obesity [9], excessive alcohol consumption [10], high consumption of red and processed meat [11], low vegetable and fruit intake [12] and tobacco smoking [13].

The attributable causes of colorectal cancer have been reported in western populations and results remained inconsistent [14-17]. A study from Japan has estimated 
that $33.6 \%$ and $31.7 \%$ colon cancer cases and deaths were attributable to the selected risk factors in 2005, including smoking, alcohol drinking, body fatness and physical inactivity [17]. A previous study in China [18] aimed to estimate the contribution of known causes of cancer in 2005, including smoking, alcohol drinking, chronic infection, nutritional factors, overweight and obesity, physical inactivity, occupational factors and hormonal factors, has showed that about $14.6 \%$ of colon cancer deaths were attributable to alcohol drinking, overweight and obesity and physical inactivity. However, previous studies of comprehensive assessment on the colorectal cancer burden in China have been limited. Moreover, the socio-economic status and lifestyle patterns have been changing in China due to the rapid development of economy.

Herein, we comprehensively evaluate the fraction of colorectal cancer cases and deaths attributable to demonstrated risk factors in China in 2012. Our results would be informative for colorectal cancer control and prevention in China and other countries with similar profiles.

\section{Methods}

\section{Overview}

Our study aimed to estimate the numbers and proportions [Population Attributable Fractions (PAFs)] of colorectal cancer incidence and mortality in China in 2012 that could be attributable to the documented risk factors. PAF is defined as the fraction of cancer that can be attributable to a risk factor. For avoidable risk factors, PAF is the proportion of cancer that can be avoided by modifying or removing the exposure of certain causal factors.

Since several studies have been published about certain exposures in China [19-21], we focused on the joint effects of these risk factors on colorectal cancer and comparing these joint effects with those found in other similar studies. Two independent investigators were involved in performing the literature searches, extracting the data and supervising statistical analyses.

\section{Colorectal cancer incidence and mortality}

Colorectal cancer incidence and mortality data in China were derived from the Globocan project in IARC in 2012. The specific data sources and methods are described in the website (http://globocan.iarc.fr/Pages/ DataSource_and_methods.aspx) [22]. Briefly, data on colorectal cancer mortality were collected from the registration system in China, while the incidence data was estimated from the known cancer deaths and Mortality and Incidence $(\mathrm{M} / \mathrm{I})$ ratio that was calculated using Poisson regression adjusted for age, gender and regional sites. In China, National Center of Cancer Register was established in 2002. In 2012, there were 222 populationbased cancer registries in China, which covered approximately $15 \%$ of the Chinese national population.

Overall, the most recent cancer facts showed that 139,000 people died from colorectal cancer in China in 2012 , with 79,000 in men and 60,000 in women separately. The incident cases of colorectal cancer was 253,000 , including 147,000 in men and 107,000 in women.

\section{Selection of risk factors}

The risk factors included in this study were those have evidence for a causal association with colorectal cancer according to two reports (Table 5 in Appendix 1). One was the World Cancer Report 2008 from the International Agency for Research on Cancer (IARC) [23], which identified dietary risk factors (high red and processed meats intake, and low vegetable and fruit intake), cigarette smoking, alcohol drinking, obesity, and physical inactivity. The second was the Colorectal Cancer 2011 Report from the Continuous Update Project (CUP) of the World Cancer Research Fund International (WCRF)that identified red or processed meats, alcohol drinking, overweight/obesity and physical inactivity as convincing risk factors, and low vegetable and fruit intake as probable risk factors for colorectal cancer [24]. We included all the convincing and probable risk factors in our study to estimate the joint effect of these exposures on colorectal cancer incidence and mortality.

\section{Prevalence of exposure data}

The current health effects of risk factors are a result of the accumulative patterns of past exposure to these risk factors, we estimated an average induction time of 1015 years for risk factors and colorectal cancer [14, 15] and therefore obtained exposure data from 1997 to 2002. Prevalence of exposure data was extracted from nationally representative studies in China (Table 6 in Appendix 1).

\section{Prevalence of tobacco smoking in China}

Tobacco smoking prevalence was abstracted from the results of a cross-sectional study in 2002 on smoking and passive smoking status in China [25]. Briefly, 145 disease surveillance points (DSPs) in 30 provinces throughout the country were selected by multi-stage random sampling method. A total of 16,056 valid records were included in the final analysis. Smokers were defined as persons who smoked at least 100 cigarettes or had ever smoked for at least 6 months. Current smokers were smoking cigarettes at the time of survey. The overall prevalence of tobacco smoking was $57.4 \%$ in men and $2.60 \%$ in women. 


\section{Prevalence of alcohol drinking in China}

Data on alcohol drinking prevalence was obtained from the 2002 National Nutrition Survey of China [26], and the specific methods of this study have been described elsewhere [27]. Briefly, the survey covered more than 240 thousand persons aged over 15 years in 31 provinces, autonomous regions and municipalities, including Hong Kong, Macao and Taiwan using the multi-stage stratified cluster random sampling method. Alcohol consumption was defined as drinking alcohol on at least 12 occasions during the past 12 months. We did not take into account the type of alcohol (beer, wine, distilled spirit) or drinking patterns (regular vs. binge drinking) due to lack of this information. Overall, the prevalence of alcohol drinking was $39.6 \%$ in men and $4.5 \%$ in women, respectively.

\section{Prevalence of physical inactivity in China}

We obtained the prevalence of physical inactivity from the International Collaborative Study of Cardiovascular Disease in Asia (InterASIA study), which conducted in the Chinese general population aged 35 to 74 years between 2000 and 2001 [28].A total of 14,933 persons completed the questionnaire and provided the nationbased prevalence of physical inactivity. Participants were asked to the number of hours per day that they devoted to vigorous or moderate or light activity, and physical inactivity was defined as participating in less than 30 min of moderate or vigorous activity per day. Results showed that $30.4 \%$ in men and $36.8 \%$ in women were physical inactivity.

\section{Prevalence of overweight and obesity}

Prevalence data on overweight and obesity were derived from the Chinese health and nutrition survey (CHNS) in 2000, which was conducted by the Chinese Academy of Preventive Medicine and the University of North Caroline Population Center [29]. The 2000 CHNS covered 15,648 participants from 9 representative provinces (54 counties) that varied in economic development, geography circumstances, public resources and health status.

Body height and weight data were obtained from the physical examination records of 2000 CHNS. We used body mass index (BMI) to evaluate the health effects of body weight, which can be calculated as the weight divided by the square of the height $\left(\mathrm{kg} / \mathrm{m}^{2}\right)$. For international comparisons, WHO recommends the following criteria: BMI at $25.0-29.9 \mathrm{~kg} / \mathrm{m}^{2}$ as "overweight" and $30 \mathrm{~kg} / \mathrm{m}^{2}$ or higher as "obesity". The estimated overall prevalence of overweight in 2000 was $15.03 \%$ in men and $16.97 \%$ in women, while the prevalence of obesity was $2.49 \%$ in men and $3.41 \%$ in women, respectively.

\section{Prevalence of dietary factors}

Prevalence data on dietary factors were also derived from the Chinese Health and Nutrition Survey in 2000 that was described earlier. Dietary factors including intake of vegetable and fruit, and intake of red and processed meats, were derived from the household survey of 2000 CHNS. These factors were achieved as continuous variables and defined as the mean per capita dietary intake, measured in Liang (equals to $50 \mathrm{~g}$ ) per day using a 24-h recall method. In our study, we categorized intake of vegetable and fruit, red and processed meats in quintiles, stratified by regions (urban and rural) and genders.

The prevalence of dietary factors varied from urban to rural areas and between genders in China. Table 1 presents the distribution of fruit, vegetable and red/processed meat intake (g/d) in 2000 in China. In urban areas, the highest quintile of vegetable intake was over $441.7 \mathrm{~g} /$ $\mathrm{d}$ in men and $400 \mathrm{~g} / \mathrm{d}$ in women, respectively. For fruit intake, the highest quintile was over $183.3 \mathrm{~g} / \mathrm{d}$ in men and over $200 \mathrm{~g} / \mathrm{d}$ in women. The highest quintile of red and processed meat intake was the same with fruit in men and over $150 \mathrm{~g} / \mathrm{d}$ in women. In rural areas, the highest quintiles of these three dietary factors intake were slightly lower than those in urban areas except for the highest quintile of fruit in women.

Table 1 Distribution of fruit, vegetable and red/processed meat intake $(\mathrm{g} / \mathrm{d})$ in 2000 in China

\begin{tabular}{|c|c|c|c|c|c|c|c|c|c|c|c|c|}
\hline \multirow[t]{2}{*}{ Quintile } & \multicolumn{3}{|l|}{ Urban men } & \multicolumn{3}{|c|}{ Urban women } & \multicolumn{3}{|l|}{ Rural men } & \multicolumn{3}{|c|}{ Rural women } \\
\hline & Vegetable & Fruit & $\begin{array}{l}\text { Red/ } \\
\text { processed } \\
\text { meat }\end{array}$ & Vegetable & Fruit & $\begin{array}{l}\text { Red/ } \\
\text { processed } \\
\text { meat }\end{array}$ & Vegetable & Fruit & $\begin{array}{l}\text { Red/ } \\
\text { processed } \\
\text { meat }\end{array}$ & Vegetable & Fruit & $\begin{array}{l}\text { Red/ } \\
\text { processed } \\
\text { meat }\end{array}$ \\
\hline 1 & $<166.7$ & $<50.0$ & $<50.0$ & $<150.0$ & $<50.0$ & $<33.3$ & $<155.0$ & $<33.3$ & $<33.3$ & $<150.0$ & $<33.3$ & $<33.3$ \\
\hline 2 & $\begin{array}{l}166.7- \\
249.9\end{array}$ & $50.0-83.2$ & $50.0-83.2$ & $\begin{array}{l}150.0- \\
224.9\end{array}$ & $50.0-83.2$ & $33.3-66.6$ & $\begin{array}{l}155.0- \\
233.2\end{array}$ & $\begin{array}{l}33.3- \\
66.6\end{array}$ & $33.3-59.9$ & $\begin{array}{l}150.0- \\
219.9\end{array}$ & $33.3-66.6$ & $33.3-49.9$ \\
\hline 3 & $\begin{array}{l}250.0- \\
324.9\end{array}$ & $\begin{array}{l}83.3- \\
116.6\end{array}$ & $\begin{array}{l}83.3- \\
119.9\end{array}$ & $\begin{array}{l}225.0- \\
299.9\end{array}$ & $\begin{array}{l}83.3- \\
116.6\end{array}$ & $66.7-99.9$ & $\begin{array}{l}233.3- \\
316.6\end{array}$ & $\begin{array}{l}\text { 66.7- } \\
88.2\end{array}$ & $60.0-86.6$ & $\begin{array}{l}220.0- \\
299.9\end{array}$ & $66.7-99.9$ & $50.0-83.2$ \\
\hline 4 & $\begin{array}{l}325.0- \\
441.6\end{array}$ & $\begin{array}{l}116.7- \\
183.2\end{array}$ & $\begin{array}{l}120.0- \\
183.2\end{array}$ & $\begin{array}{l}300.0- \\
399.9\end{array}$ & $\begin{array}{l}116.7- \\
199.9\end{array}$ & $\begin{array}{l}100.0- \\
149.9\end{array}$ & $\begin{array}{l}316.7- \\
433.2\end{array}$ & $\begin{array}{l}88.3- \\
176.6\end{array}$ & $\begin{array}{l}86.7- \\
136.6\end{array}$ & $\begin{array}{l}300.0- \\
399.9\end{array}$ & $\begin{array}{l}100.0- \\
233.2\end{array}$ & $\begin{array}{l}83.3- \\
116.6\end{array}$ \\
\hline 5 & $\geq 441.7$ & $\geq 183.3$ & $\geq 183.3$ & $\geq 400.0$ & $\geq 200.0$ & $\geq 150.0$ & $\geq 433.3$ & $\geq 176.7$ & $\geq 136.7$ & $\geq 400.0$ & $\geq 233.3$ & $\geq 116.7$ \\
\hline
\end{tabular}

Data were extracted from the Chinese health and nutrition survey (CHNS) in 2000 [29] 


\section{Relative risk (RR) data}

Data on the RRs of different risk factors and risk of colorectal cancer in this study was derived from epidemiologic studies through a systematic search of publications, including: PubMed, Web of Science, websites, and China National Knowledge Infrastructure (CNKI). The selection criteria for RRs should include relative risks or odds ratios and the corresponding 95\% confidence intervals (CIs). Language was limited to English or Chinese only. The highest priority was given to those meta-analyses or largescale cohort studies in the Chinese population. When such studies were not available, we used meta-analyses of other Asian or non-Asian populations. Furthermore, if RRs for men and women were not available separately, we assumed the RRs for both men and women were equal. All RRs used in our study were statistically significant.

RR for tobacco smoking was from a meta-analysis of 22 cohort studies in Asian and other populations [30], and RR for alcohol drinking was derived from a population-based cohort study in the Chinese population [31]. However, RRs for overweight and obesity were obtained from the Asia-Pacific Cohort Studies Collaboration in Asian and other populations [32], and RR for physical inactivity was from a meta-analysis included 53 studies in Asian and other populations [33].

RRs for vegetable and fruit [12] and red or processed meat intake [11] were abstracted from two large studies of meta-analyses on the dose-response association with colorectal cancer incidence. These two studies both estimated the RRs for every $100 \mathrm{~g} /$ day increase. The RRs calculated in our study were first transformed onto a log scale and divided by 100 to give the $\log \mathrm{RR} / \mathrm{g}$ per day, then multiplied by the lower intake of every quintile. Finally, the RRs in other quintiles was divided by that in quintile 5 (fruit or vegetable) or in quintile 1(red or processed meat) to get the final estimates. The RR in quintile 5 (fruit or vegetable) or in quintile 1(red or processed meat) was assumed to be equal to 1 .

Table 2 shows RRs and 95\% CIs for the selected risk factors and risk of colorectal cancer. RR for smoking (current vs. never) from the meta-analysis was 1.16 (95\% $\mathrm{CI}, 1.09,1.24)$ and as compared with non-drinkers, the combined RR for drinkers was 1.24 (95\% CI, 1.01, 1.54) for both sexes. For overweight and obesity, the RRs were $1.25(95 \% \mathrm{CI}, 1.07,1.45)$ and $1.57(95 \% \mathrm{CI}, 1.23,2.00)$ for both men and women. For physical inactivity, the RRs were 1.32 for men and 1.27 for women, respectively. For the lowest quintile of vegetable intake, RRs were similar among urban and rural men and women (1.52 vs. 1.46 for urban men and women, 1.50 vs. 1.46 for rural men and women). For the lowest quintile of fruit intake, the RRs were 1.12 and 1.13 among urban men and women, and the corresponding figures were 1.12 and 1.16 among rural men and women. When considering the highest intake of red and processed meat, the RRs were 1.27 among urban men and 1.22 among urban women, and the corresponding figures were 1.20 in rural men and 1.17 in rural women, respectively.

\section{Statistical analysis}

PAF was estimated based on the RR of cancer associated with exposure to a particular risk factor and the prevalence of exposure to the risk factor in a general population (P). The colorectal cancer-specific PAF for different exposures for 2012 was calculated using Levin's formula [34]:

$$
\mathrm{PAF}=\frac{\mathrm{P} \times(\mathrm{RR}-1)}{[\mathrm{P} \times(\mathrm{RR}-1)]+1}
$$

PAFs for low intake of vegetable and fruit and high intake of red or processed meat were calculated by a shift of all to the top quintile, which is a full shift, by the following formula:

$$
\mathrm{PAF}=\frac{\sum_{i=1}^{n} P_{i}\left(R R_{i}-1\right)}{\sum_{i=1}^{n} P_{i}\left(R R_{i}-1\right)+1}
$$

$\mathrm{RR}_{\mathrm{i}}$ was the relative risk at quintile $\mathrm{i}(i=1,2,3,4,5)$.

$P_{i}$ was the prevalence of quintile $i$ in a full shift, which was $20 \%$.

Combined PAF for risk factors in our study including smoking, alcohol drinking, overweight/obesity, physical inactivity, low vegetable and fruit intake, and high red and processed meat intake can be estimated by the following formula [35]:

$$
\begin{aligned}
\mathrm{PAF}= & 1-\left(1-\mathrm{PAF}_{1}\right) \times\left(1-\mathrm{PAF}_{2}\right) \times\left(1-\mathrm{PAF}_{3}\right) \\
& \times\left(1-\mathrm{PAF}_{4}\right) \times\left(1-\mathrm{PAF}_{5}\right) \times\left(1-\mathrm{PAF}_{6}\right) \\
& \times\left(1-\mathrm{PAF}_{7}\right)
\end{aligned}
$$

Where $\mathrm{PAF}_{1}$ is the PAF for exposure to tobacco smoking, $\mathrm{PAF}_{2}$ is the PAF for exposure to alcohol drinking, $\mathrm{PAF}_{3}$ is the PAF for exposure to overweight and obesity, $\mathrm{PAF}_{4}$ is the PAF for exposure to physical inactivity, $\mathrm{PAF}_{5}$ and $\mathrm{PAF}_{6}$ are the PAFs for exposure to low vegetable and fruit intake, and $\mathrm{PAF}_{7}$ is the PAF for exposure to high red and processed meat intake.

In addition, considering the uncertainty in the estimation of PAF resulting from RR and prevalence of exposure, a delta method was used in the standard formula for estimating the $95 \%$ CI of PAF [36].

\section{Results}

The PAFs of colorectal cancer incidence and mortality are listed in Table 3. Tobacco smoking was responsible for 6636 deaths and 12,348 incident cases of colorectal cancer in men with a PAF of $8.4 \%$ (95\% CI, $4.9 \%, 12.1 \%)$; and for women, the corresponding deaths and cases were only 240 and 428 with a PAF of $0.4 \%(95 \% \mathrm{CI}$, 
Table 2 Relative risks (RRs) and 95\% confidence intervals (Cls) between selected risk factors and risk of colorectal cancer

\begin{tabular}{|c|c|c|c|c|}
\hline \multirow[t]{2}{*}{ Risk factors } & \multicolumn{3}{|l|}{ RR $(95 \%$ Cl) } & \multirow[t]{2}{*}{ Sources } \\
\hline & Men & Women & Design & \\
\hline Smoking & $1.16(1.09-1.24)$ & $1.16(1.09-1.24)$ & Meta-analysis & 30 \\
\hline Alcohol drinking & $1.24(1.01-1.54)$ & $1.24(1.01-1.54)$ & Cohort study & 31 \\
\hline Overweight & $1.25(1.07-1.45)$ & $1.25(1.07-1.45)$ & Cohort study & 32 \\
\hline Obesity & $1.57(1.23-2.00)$ & $1.57(1.23-2.00)$ & & \\
\hline Physical inactivity & $1.32(1.23-1.41)$ & $1.27(1.17-1.41)$ & Meta-analysis & 33 \\
\hline $\begin{array}{l}\text { Vegetable intake } \\
\text { Urban }\end{array}$ & & & & 12 \\
\hline Quintile 5 & 1.00 & 1.00 & & \\
\hline Quintile 4 & $1.12(1.04-1.19)$ & $1.10(1.03-1.16)$ & & \\
\hline Quintile 3 & $1.20(1.06-1.34)$ & $1.18(1.05-1.30)$ & & \\
\hline Quintile 2 & $1.30(1.09-1.51)$ & $1.27(1.08-1.46)$ & & \\
\hline Quintile 1 & $1.52(1.14-1.95)$ & $1.46(1.13-1.83)$ & & \\
\hline $\begin{array}{l}\text { Vegetable intakea: } \\
\text { rural }\end{array}$ & & & Meta-analysis & 12 \\
\hline Quintile 5 & 1.00 & 1.00 & & \\
\hline Quintile 4 & $1.12(1.04-1.19)$ & $1.10(1.03-1.16)$ & & \\
\hline Quintile 3 & $1.21(1.06-1.35)$ & $1.19(1.06-1.31)$ & & \\
\hline Quintile 2 & $1.30(1.09-1.52)$ & $1.27(1.08-1.46)$ & & \\
\hline Quintile 1 & $1.50(1.14-1.92)$ & $1.46(1.13-1.83)$ & & \\
\hline $\begin{array}{l}\text { Fruit intake }{ }^{a} \text { : } \\
\text { urban }\end{array}$ & & & Meta-analysis & 12 \\
\hline Quintile 5 & 1.00 & 1.00 & & \\
\hline Quintile 4 & $1.04(1.01-1.07)$ & $1.05(1.02-1.09)$ & & \\
\hline Quintile 3 & $1.06(1.02-1.11)$ & $1.07(1.02-1.13)$ & & \\
\hline Quintile 2 & $1.09(1.03-1.15)$ & $1.10(1.03-1.17)$ & & \\
\hline Quintile 1 & $1.12(1.04-1.21)$ & $1.13(1.04-1.23)$ & & \\
\hline Fruit intake $e^{a}$ : rural & & & Meta-analysis & 12 \\
\hline Quintile 5 & 1.00 & 1.00 & & \\
\hline Quintile 4 & $1.06(1.02-1.10)$ & $1.09(1.03-1.15)$ & & \\
\hline Quintile 3 & $1.07(1.02-1.12)$ & $1.11(1.03-1.19)$ & & \\
\hline Quintile 2 & $1.09(1.03-1.16)$ & $1.13(1.04-1.23)$ & & \\
\hline Quintile 1 & $1.12(1.04-1.20)$ & $1.16(1.05-1.28)$ & & \\
\hline $\begin{array}{l}\text { Red and processed } \\
\text { meat } t^{2} \text { urban }\end{array}$ & & & Meta-analysis & 11 \\
\hline Quintile 1 & 1.00 & 1.00 & & \\
\hline Quintile 2 & $1.07(1.02-1.11)$ & $1.04(1.01-1.07)$ & & \\
\hline Quintile 3 & $1.12(1.03-1.20)$ & $1.09(1.03-1.15)$ & & \\
\hline Quintile 4 & $1.17(1.05-1.29)$ & $1.14(1.04-1.24)$ & & \\
\hline Quintile 5 & $1.27(1.07-1.48)$ & $1.22(1.06-1.38)$ & & \\
\hline Red and processed meat ${ }^{a}$ : rural & & & Meta-analysis & 11 \\
\hline Quintile 1 & 1.00 & 1.00 & & \\
\hline Quintile 2 & $1.04(1.01-1.07)$ & $1.04(1.01-1.07)$ & & \\
\hline Quintile 3 & $1.08(1.02-1.14)$ & $1.07(1.02-1.11)$ & & \\
\hline Quintile 4 & $1.12(1.03-1.21)$ & $1.12(1.03-1.20)$ & & \\
\hline Quintile 5 & $1.20(1.06-1.34)$ & $1.17(1.05-1.29)$ & & \\
\hline
\end{tabular}

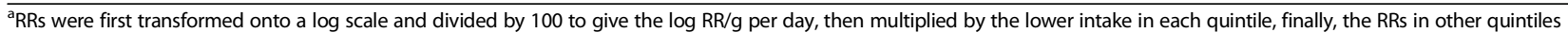
were divided by that in quintile 5 (vegetable and fruit) or quintile 1 (red and processed meat) to get the final RRs, and the RR in quintile 5 (vegetable and fruit) or quintile 1 (red and processed meat) was assumed to be equal to 1

$0.2 \%, 0.6 \%)$. The fraction of colorectal cancer incidence and mortality caused by alcohol drinking was $8.7 \%$ for men $(95 \% \mathrm{CI}, 0.4 \%, 17.6 \%)$ and $1.1 \%$ for women $(95 \%$
CI, $0.0 \%, 2.4 \%)$. The corresponding figures were 6873 deaths and 12,789 incident cases in men and 660 deaths and 1177 incident cases in women. The estimates of 
Table 3 Colorectal cancer mortality and incidence attributable to the selected risk factors in China, 2012

\begin{tabular}{|c|c|c|c|c|c|c|c|c|c|}
\hline \multirow[t]{2}{*}{ Risk factors } & \multicolumn{3}{|l|}{ Men } & \multicolumn{3}{|l|}{ Women } & \multicolumn{3}{|l|}{ Total } \\
\hline & $\overline{\operatorname{PAF}(95 \% \mathrm{Cl})^{\mathrm{a}}(\%)}$ & Mortality & $\overline{\text { Incidence }}$ & $\overline{\operatorname{PAF}(95 \% \mathrm{CI})^{\mathrm{a}}(\%)}$ & Mortality & $\overline{\text { Incidence }}$ & $\overline{\operatorname{PAF}(95 \% \mathrm{Cl})^{\mathrm{a}}(\%)}$ & Mortality & $\overline{\text { Incidence }}$ \\
\hline Tobacco smoking & $8.4(4.9-12.1)$ & 6636 & 12,348 & $0.4(0.2-0.6)$ & 240 & 428 & $4.9(2.9-7.1)$ & 6876 & 12,776 \\
\hline Alcohol drinking & $8.7(0.4-17.6)$ & 6873 & 12,789 & $1.1(0.0-2.4)$ & 660 & 1177 & $5.4(0.2-11.0)$ & 7533 & 13,966 \\
\hline Overweight/Obesity & $4.9(1.6-8.5)$ & 3871 & 7203 & 5.8(1.9-9.9) & 3480 & 6206 & $5.3(1.7-9.1)$ & 7351 & 13,409 \\
\hline Physical inactive & $8.9(6.5-11.1)$ & 7031 & 13,083 & $9.0(5.9-13.1)$ & 5400 & 9630 & $8.9(6.1-22.2)$ & 12,431 & 22,713 \\
\hline Low vegetable intake & 18.8(6.2-29.1) & 14,852 & 27,636 & 16.8(5.7-25.9) & 10,080 & 17,976 & 17.9(3.7-17.1) & 24,932 & 45,612 \\
\hline Low fruit intake & $6.2(2.2-10.4)$ & 4898 & 9114 & $6.7(2.3-11.2)$ & 4020 & 7169 & $6.4(2.5-13.2)$ & 8918 & 16,283 \\
\hline $\begin{array}{l}\text { High red and } \\
\text { processed meat intake }\end{array}$ & $9.1(2.7-14.8)$ & 7189 & 13,377 & $7.9(2.2-12.7)$ & 4740 & 8453 & $8.6(2.5-13.9)$ & 11,929 & 21,830 \\
\hline Total $^{\mathrm{b}}$ & $49.8(22.2-68.1)$ & 39,342 & 73,206 & $39.6(17.1-56.4)$ & 23,760 & 42,372 & $45.5(18.1-63.8)$ & 63,102 & 115,578 \\
\hline
\end{tabular}

PAF for overweight and obesity was $4.9 \%$ (95\% CI, 1.6\%, $8.5 \%)$ in men and $5.8 \%$ (95\% CI, 1.9\%, 9.9\%) in women. Furthermore, physical inactivity was responsible for $8.9 \%$ of colorectal cancer incidence and mortality in men (95\% CI, 6.5\%, 11.1\%) and 9.0\% (95\% CI, 5.9\%, 13.1\%) in women. When increasing vegetable and fruit consumption, we could save 33,850 of colorectal cancer deaths and 61,895 incident colorectal cancer cases (PAF $=17.9 \%$ for low vegetable intake and $6.4 \%$ for low fruit intake). High red and processed meat intake was responsible for $8.6 \%(2.5 \%, 13.9 \%)$ of colorectal cancer incidence and mortality (PAF $=9.1 \%$ for men and $7.9 \%$ for women). Overall, we estimated that $63,102(\mathrm{PAF}=45.5 \%$; 95\% CI: $18.1 \%, 63.8 \%)$ of the total colorectal cancer deaths, including 39,342 of the deaths in men and 23,760 deaths in women, and 115,578 incident colorectal cancer cases (73,206 in men and 42,372 in women) in 2012 were attributable to the combined effects of the selected risk factors.

\section{Discussion}

Our study is for the first time to comprehensively estimate the burden of colorectal cancer incidence and mortality attributable to the known risk factors in China. Overall, we estimated that $45.5 \%$ of colorectal cancer incidence and mortality $(49.8 \%$ in men and $39.6 \%$ in women, respectively) were attributable to the selected environmental risk factors in China in 2012, including tobacco smoking, alcohol drinking, overweight/obesity, physical inactivity and dietary factors. Our results showed that PAFs of smoking and alcohol drinking were $8.4 \%$ and $8.7 \%$ in men, and $0.4 \%$ and $1.1 \%$ in women, respectively. Low vegetable intake was responsible for the most incidence and mortality of colorectal cancer for both genders, with $18.8 \%$ in men and $16.8 \%$ in women.
We compared our estimates of the fraction of joint avoidable causes of colorectal cancer with similar estimates from previous studies in different countries as showed in Table 4. PAFs for colorectal cancer in our study were higher than the corresponding estimates in the worldwide study [37], French study [14], and Japan study [17], but a little lower than that in the UK study [15]. The discrepancy of PAFs in these studies could be explained by the selected risk factors, source of data on the prevalence and RR, and genetic diversity. For instance, tobacco smoking and alcohol drinking among women are much lower in China compared with other Asian (such as Japan) and European populations (such as France).

Tobacco smoking, as a cause of cancer, is common in China. Tobacco smoking was responsible for five million deaths in 2000, with $50 \%$ of these deaths in low and middle income countries. Zheng and his colleagues examined the burden of tobacco smoking-related deaths in Asia [38], which indicated that $3.1 \%$ of colorectal cancer deaths among mainland Chinese women were attributable to smoking. Reasons for the discrepancy of PAF may be explained by the different sources of prevalence and RR in these studies. In Zheng's study, the prevalence of smoking was from a cross-sectional survey conducted in 1990s, and RR was estimated from four cohort studies in mainland China among subjects over 44 years; while in our study, the prevalence data was derived from a national survey in 2002, and RR was obtained from the combined findings in a meta-analysis. We also conducted a sensitivity analysis using the smoking prevalence in 1997 (assumed a lag-time of 15 years) to estimate PAF, and our results remained robust with respect to different lag-time.

Alcohol consumption is causally associated with the increased risk of certain cancers, including colorectal 
Table 4 Comparison of Population Attributable Fraction (PAF, \%) of colorectal cancer mortality and incidence attributable of modified risk factors in various studies

\begin{tabular}{|c|c|c|c|c|}
\hline Studies & Men & Women & Total & Risk factors included \\
\hline Our study ${ }^{a}$ & 49.8 & 39.6 & 45.5 & $\begin{array}{l}\text { Tobacco smoking, alcohol drinking, } \\
\text { overweight and obesity, physical inactivity, } \\
\text { high red and processed meat intake, low } \\
\text { fruit and vegetable intake }\end{array}$ \\
\hline Worldwide study ${ }^{a}[37]$ & - & - & 13.0 & \multirow{3}{*}{$\begin{array}{l}\text { Overweight and obesity, physical inactivity, } \\
\text { low fruit and vegetable intake }\end{array}$} \\
\hline $\begin{array}{l}\text { Low and middle } \\
\text { income countries }^{\mathrm{a}}\end{array}$ & - & - & 11.0 & \\
\hline $\begin{array}{l}\text { High income } \\
\text { countries }^{\mathrm{a}}\end{array}$ & - & - & 15.0 & \\
\hline French study ${ }^{\mathrm{a}}[14]$ & 21.3 & 16.0 & 18.8 & $\begin{array}{l}\text { Alcohol drinking, obesity and overweight } \\
\text { and physical inactivity }\end{array}$ \\
\hline UK study ${ }^{\mathrm{a}}[15]$ & 56.5 & 51.9 & 54.4 & $\begin{array}{l}\text { Tobacco smoking, alcohol drinking, intake } \\
\text { of meat and fibre, overweight and obesity, } \\
\text { Physical excises, infections and radiation- } \\
\text { ionizing }\end{array}$ \\
\hline \multicolumn{4}{|l|}{ Japan study [17] } & \multirow{3}{*}{$\begin{array}{l}\text { Tobacco smoking, alcohol drinking, } \\
\text { overweight and obesity and physical } \\
\text { inactivity }\end{array}$} \\
\hline Colon & 51.0 & 12.8 & 33.6 & \\
\hline Rectum & 46.6 & 6.5 & 31.5 & \\
\hline
\end{tabular}

aAFs for colorectal cancer

cancer. A previous study in China has evaluated the role of alcohol on the cancer burden in 2005 and showed that PAFs of colorectal cancer were $2.06 \%$ in men and $0.15 \%$ in women based on the 1991 drinking habits [19], while the corresponding PAFs were $2.32 \%$ in men and $0.27 \%$ in women based on the prevalence in 2002 . The RR used in Liang's study was extracted from a metaanalysis in China in 2003 and the value was not statistically significant. The increased trend of PAFs with years was observed in her study, which may explain the much higher PAFs in our estimates calculated based on the increased prevalence of 2002 drinking habits. A sensitivity analysis for estimating PAF using the prevalence in 1997 did not alter our results, which remained also robust with respect to different lag-time.

Few studies can be available for PAF of colorectal cancer attributable to overweight and obesity and physical inactivity in China. Only one similar study was available in China [20], and showed that overweight and obesity were responsible for $0.7 \%$ of colorectal cancer deaths for men and $1.5 \%$ of rectal cancer deaths for women in 2005, which were lower than our estimates. Our study indicated that overweight and obesity caused $4.9 \%$ of colorectal cancer deaths in men and $5.8 \%$ in women, respectively. Moreover, Wang's study [20] estimated that $23.7 \%$ of colon cancer among urban men and $11.0 \%$ among urban women were attributable to physical inactivity. The corresponding PAFs in our study were $8.9 \%$ in men and $9.0 \%$ in women for both urban and rural areas. The difference for PAF could be explained by the source of prevalence of physical inactivity.
Many previous studies have reported the combined effect of both fruit and vegetable intake on cancer burden, but no studied can be available for the effect of red and processed meat on colorectal cancer incidence and mortality. To our knowledge, our study was for the first time to estimate the PAF for high red and processed meat intake in China. All the selected dietary factors were responsible for $31.4 \%$ of colorectal cancer incidence and mortality, which showed a quite large combined effect. However, Danaei and his colleagues found that only $2 \%$ of colorectal cancer deaths in low and middle income countries were attributable to low fruit intake and low vegetable intake [37], reflecting the different sources of RRs and exposure rates in these two studies.

The strengths of our study included first systematic assessment of colorectal cancer causes, prevalence data from nationally representative studies, and new national data on colorectal cancer incident cases and deaths. However, our results have several limitations. First, several other known risk factors of colorectal cancer exist but have not been included in our study. For example, further emerging evidence suggests that infection with Helicobacter pylori, Fuso bacterium species, and other potential infectious agents might be associated with an increased risk of colorectal cancer [39-41], but their causal relationships with colorectal cancer risk are unclear. Furthermore, epidemiological studies have consistently shown an inverse association between serum vitamin D concentrations and risk of colorectal cancer, but whether 
and to what extent this association is causal needs to be established [42]. Even the selected risk factors in our study can also be classified into more specific groups, for example, smokers can be divided into former smokers and current smokers; type of alcohol drinking can be divided into beer, spirit and others, which can also affect our estimates. Therefore, future studies are still needed to evaluate the contribution of these risk factors and others to the burden of colorectal cancer in China. Second, some sources used for PAF calculations might be uncertain. For data on prevalence, self-reported questionnaires may lead to underestimation of prevalence of exposure (such as smoking and alcohol consumption), which may underestimate the PAFs in our study. These data were extracted from different studies in China, which may also affect our PAF estimates. For relative risks used in PAF calculations, the best priority should be given to the meta-analyses included all related studies in China, but prospective cohort studies in China were used as a substitute for certain risk factors due to lack of the nation-based meta-analyses. For dietary factors, we derived RRs from a meta-analysis in the worldwide population. As a result, there could be uncertainty in the extrapolation of these RRs to the Chinese population. The direction and potential magnitude of potential bias could not be evaluated as well. Moreover, we used equal RRs for both genders when data for men and women separately were unavailable, but the RRs for men and women might be different in reality that could make our result statistical instability. Third, we did not adjust the PAFs for the potential interaction of the selected risk factors because few data from China can be available to provide the accurate RRs for interaction between these risk factors. Combined PAF for seven risk factors, however, was estimated in our study.

\section{Conclusions}

In summary, our study represents a systematic assessment of the burden of tobacco smoking, alcohol drinking, overweight/obesity, physical inactivity, low fruit intake, low vegetable intake and high red and processed meat intake on colorectal cancer incidence and mortality in China. Approximately $46 \%$ of colorectal cancer incidence and mortality in the Chinese population were attributable to these seven risk factors in 2012. This report reinforces the notion that increasing vegetable and fruit intake and reducing red and processed meat intake are by far the main avenues for reducing the burden of colorectal cancer in China, but other risk factors, including alcohol drinking and physical inactivity, should not be neglected.

\section{Appendix 1}

Table 5 Risk factors of colorectal cancer included in the study

\begin{tabular}{|c|c|}
\hline Risk factors & $\begin{array}{l}\text { Definition of theoretical minimum } \\
\text { risk exposure }\end{array}$ \\
\hline Tobacco Smoking & Never smoking \\
\hline Alcohol drinking & $\begin{array}{l}\text { Less than } 12 \text { occasions during the past } \\
12 \text { months }\end{array}$ \\
\hline Overweight and Obesity & Body mass index $<25 \mathrm{~kg} / \mathrm{m}^{2}$ \\
\hline Physical inactivity & $\begin{array}{l}\text { less than } 30 \text { min of moderate or vigorous } \\
\text { activity per day }\end{array}$ \\
\hline Low vegetable intake & Higher than the lowest quintile group \\
\hline Low fruit intake & Higher than the lowest quintile group \\
\hline $\begin{array}{l}\text { High red and processed } \\
\text { meat intake }\end{array}$ & Lower than the highest quintile group \\
\hline
\end{tabular}

Table 6 Prevalence of smoking, alcohol drinking, overweight, obesity and physical inactivity in China around 2000

\begin{tabular}{lllll}
\hline Risk factors & Men (\%) & Women (\%) & Year & Reference \\
\hline Tobacco Smoking & 57.4 & 2.6 & 2002 & 25 \\
Alcohol drinking & 39.6 & 4.5 & 2002 & 26 \\
Physical inactivity & 30.4 & 36.8 & 2000 & 28 \\
Overweight & 15.0 & 17.0 & 2000 & 29 \\
Obesity & 2.5 & 3.4 & 2000 & 29 \\
\hline
\end{tabular}

\section{Abbreviations}

95\% Cl: 95\% confidence interval; BMI: Body mass index; PAF: Population attributable fraction; RR: Relative risk

\section{Acknowledgements}

Not applicable.

\section{Funding}

This work was supported by Natural Science Foundation of Zhejiang Province (Hangzhou, China, Grant number: 519,600 + N21601) and Zhejiang University (Hangzhou, China, Grant number: 519600*172210141). The sponsor of the study had no role in study design, data collection, data analysis, data interpretation, decision to publish or preparation of the manuscript.

Availability of data and materials

The dataset supporting the conclusions of this article is available on request from e-mail: wangjianbing1980@yahoo.com.

\section{Authors' contributions \\ $\mathrm{KC}$ and JBW conceived of the study, and participated in its design and coordination. MJG, QCH performed the literature searches, and conducted statistical analyses, and drafted the manuscript, which was edited by KC and JBW. CZB, DY, YJL, ZHY and XQL participated in the original searching work and data collection. All authors read and approved the final manuscript.}

\section{Competing interest}

The authors declare that they have no competing interests.

Ethics approval and consent to participate

Not applicable.

Consent for publication

Not applicable. 


\section{Publisher's Note}

Springer Nature remains neutral with regard to jurisdictional claims in published maps and institutional affiliations.

\section{Author details}

${ }^{1}$ Department of Epidemiology and Health Statistics, Zhejiang University School of Public Health, 866 Yuhangtang Road, Hangzhou 310058, China. ${ }^{2}$ Sir Run Run Shaw Hospital, School of Medicine, Zhejiang University, Hangzhou 310058, China. 'School infirmary of Zhejiang University, Hangzhou 310058, China

\section{Received: 28 April 2016 Accepted: 21 December 2017}

\section{Published online: 05 January 2018}

\section{References}

1. Ferlay J, Soerjomataram I, Ervik M, Dikshit R, Eser S, Mathers C, Rebelo M, Parkin DM, Forman D, Bray F. GLOBOCAN 2012 v1.0, cancer incidence and mortality worldwide: IARC Cancer Base no. 11: Lyon, International Agency for Research on Cancer; 2013. Available from http://globocan.iarc.fr.

2. Siegel R, DeSantis C, Virgo K, Stein K, Mariotto A, Smith T, et al. Cancer treatment and survivorship statistics, 2012. CA Cancer J Clin. 2012;62:220-41.

3. Center MM, Jemal A, Smith RA, Ward E. Worldwide variations in colorectal cancer. CA Cancer J Clin. 2009;59:366-78.

4. Brenner H, Kloor M, Pox CP. Colorectal cancer. Lancet. 2014:383:1490-502.

5. Albano JD, Ward E, Jemal A, Anderson R, Cokkinides VE, Murray T, et al. Cancer mortality in the United States by education level and race. J Natl Cancer Inst. 2007;99:1384-94.

6. Taylor DP, Burt RW, Williams MS, Haug PJ, Cannon-Albright LA. Populationbased family history-specific risks for colorectal cancer: a constellation approach. Gastroenterology. 2010;138:877-85.

7. Jess T, Rungoe C, Peyrin-Biroulet L. Risk of colorectal cancer in patients with ulcerative colitis: a meta-analysis of population-based cohort studies. Clin Gastroenterol Hepatol. 2012;10:639-45.

8. Jiang Y, Ben Q, Shen H, Lu W, Zhang Y, Zhu J. Diabetes mellitus and incidence and mortality of colorectal cancer: a systematic review and metaanalysis of cohort studies. Eur J Epidemiol. 2011;26:863-76.

9. Ma Y, Yang Y, Wang F, Zhang P, Shi C, Zou Y, et al. Obesity and risk of colorectal cancer: a systematic review of prospective studies. PLoS One. 2013;8:e53916.

10. Fedirko V, Tramacere I, Bagnardi V, Rota M, Scotti L, Islami F, et al. Alcohol drinking and colorectal cancer risk: an overall and dose-response metaanalysis of published studies. Ann Oncol. 2011;22:1958-72.

11. Chan DS, Lau R, Aune D, Vieira R, Greenwood DC, Kampman E, et al. Red and processed meat and colorectal cancer incidence: meta-analysis of prospective studies. PLoS One. 2011;6:e20456.

12. Riboli $E$, Norat T. Epidemiologic evidence of the protective effect of fruit and vegetables on cancerrisk. Am J Clin Nutr. 2003;78:559S-69S.

13. Liang PS, Chen TY, Giovannucci E. Cigarette smoking and colorectal cancer incidence and mortality: systematic review and meta-analysis. Int J Cancer. 2009:124:2406-15.

14. IARC (International Agency for Research on Cancer). IARC working group reports, Vol 3, attributable causes of cancer in France in the year 2000. Lyon: IARC Press; 2007

15. Parkin DM, Boyd L, Walker LC. 16. The fraction of cancer attributable to lifestyle and environmental factors in the UK in 2010. Br J Cancer. 2011; 105:S77-81

16. Olsen JH, Andersen A, Dreyer L, Pukkala E, Tryggvadottir L, Gerhardsson de Verdier M, et al. Summary of avoidable cancers in the Nordic countries. APMIS Suppl. 1997;76:141-6.

17. Inoue M, Sawada N, Matsuda T, Iwasaki M, Sasazuki S, Shimazu T, et al. Attributable causes of cancer in Japan in 2005-systematic assessment to estimate current burden of cancer attributable to known preventable risk factors in Japan. Ann Oncol. 2012;23:1362-9.

18. Wang JB, Jiang $Y$, Liang H, Li P, Xiao HJ, Ji J, et al. Attributable causes of cancer in China. Ann Oncol. 2012;23:2983-9.

19. Liang $\mathrm{H}$, Wang J, Xiao H, Wang D, Wei W, Qiao Y, et al. Estimation of cancer incidence and mortality attributable to alcohol drinking in China. BMC Public Health. 2010;10:730

20. Wang $D$, Zheng $W$, Wang $S M$, Wang JB, Wei $W Q$, Liang $H$, et al. Estimation of cancer incidence and mortality attributable to overweight, obesity, and physical inactivity in China. Nutr Cancer. 2012;64:48-56.
21. Xiao HJ, Liang $H$, Wang JB, Huang CY, Wei WQ, Boniol M, et al. Attributable causes of cancer in china: fruit and vegetable. Chin J Cancer Res. 2011;23:171-6.

22. International Agency for Research on Cancer. GLOBOCAN 2012: Estimated Cancer Incidence, Mortality and Prevalence Worldwide in 2012. http:// globocan.iarc.fr/Pages/DataSource_and_methods.aspx, Accessed 2 Jul 2014.

23. World cancer report 2008. Lyon, France: International Agency for Research on Cancer, 2008. http://www.iarc.fr/en/publications/pdfs-online/wcr/2008/. Accessed 6 Jul 2014

24. World Cancer Research Fund / American Institute for Cancer Research. Colorectal Cancer 2011 Report: Food, Nutrition, Physical Activity, and the Prevention of Colorectal Cancer. http://www.wcrf.org/int/research-we-fund/ continuous-update-project-findings-reports/colorectal-bowel-cancer. Accessed 8 July 2014.

25. Yang G, Ma J, Liu N, Zhou L. Smoking and passive smoking in Chinese, 2002. Zhonghua Liu Xing Bing Xue Za Zhi. 2005;26:77-83.

26. Ma GS. The nutrition and health status of the Chinese people: behaviors and lifestyle in 2002. Beijing: People Health Press; 2006.

27. Yang $X$, Kong L, Zhai F, Ma G, Jin S. The overall scheme of China health and nutrition survey. Zhonghua Liu Xing Bing Xue Za Zhi. 2005;26:471-4.

28. Muntner P, Gu D, Wildman RP, Chen J, Qan W, Whelton PK, et al. Prevalence of physical activity among Chinese adults: results from the international collaborative study of cardiovascular disease in Asia. Am J Public Health. 2005:95:1631-6.

29. National Institute of Nutrition and Food Safety, China Center for Disease Control and Prevention, Carolina Population Center, the University of NorthCarolina at Chapel Hill, the NIH and the Fogarty International Center China Health and Nutrition Survey; 2000. http://www.cpc.unc.edu/projects/ china. Accessed 21 Oct 2014.

30. Huxley RR, Ansary-Moghaddam A, Clifton P, Czernichow S, Parr CL, Woodward M. The impact of dietary and lifestyle risk factors on risk of colorectal cancer: a quantitative overview of the epidemiological evidence. Int J Cancer. 2009;125:171-80.

31. Tsong WH, Koh WP, Yuan JM, Wang R, Sun CL, Yu MC. Cigarettes and Alcohol in relation to colorectal cancer: the Singapore Chinese health study. Br J Cancer. 2007;96:821-7.

32. Parr CL, Batty GD, Lam TH, Barzi F, Fang X, Ho SC, et al. Body-mass index and cancer mortality in the Asia-Pacific cohort studies collaboration: pooled analyses of 424,519 participants. Lancet Oncol. 2010;11:741-52.

33. Wolin KY, Yan Y, Colditz GA, Lee IM. Physical activity and colon cancer prevention: a meta-analysis. Br J Cancer. 2009;100:611-6.

34. Levin ML. The occurrence of lung cancer in man. ACTA. 1953;9:531-41.

35. Ezzati M, Vander Hoorn S, Rodgers A, Lopez AD, Mathers CD, Murray CJL. Estimates of global and regional potentil health gains from reducing muliple major risk factors. Lancet. 2003;362:271-80.

36. Klein LR. A textbook of econometrics. New York: Row, Peterson and Company; 1953.

37. Danaei G, Vander Hoorn S, Lopez AD, Murray CJL, Ezzati M. Causes of cancer in the world: comparative risk assessment of nine behavioural and environmental risk factors. Lancet. 2005;366:1784-93.

38. Zheng W, McLerran DF, Rolland BA, Fu Z, Boffetta P, He J, et al. Burden of total and cause-specific mortality related to tobacco smoking among adults aged $>/=45$ years in Asia: a pooled analysis of 21 cohorts. PLoS Med. 2014; 11:e1001631.

39. Sonnenberg A, Genta RM. Helicobacter pylori is a risk factor for colonic neoplasms. Am J Gastroenterol. 2013;108:208-15.

40. Kostic AD, Gevers D, Pedamallu CS, Michaud M, Duke F, Earl AM, et al. Genomic analysis identifies association of Fusobacterium with colorectal carcinoma. Genome Res. 2012:22:292-8.

41. Boleij A, van Gelder MM, Swinkels DW, Tjalsma H. Clinical importance of streptococcus gallolyticus infection among colorectal cancer patients: systematic review and meta-analysis. Clin Infect Dis. 2011;53:870-8.

42. Ma Y, Zhang P, Wang F, Yang J, Liu Z, Qin H. Association between vitamin $D$ and risk of colorectal cancer: a systematic review of prospective studies. J Clin Oncol. 2011;29:3775-82. 